\title{
THE EFFECT OF 8-PHASE ON CRACK PROPAGATION UNDER CREEP AND FATIGUE CONDITIONS IN ALLOY 718
}

\author{
Shuqi Li, Jingyun Zhuang, Jinyan Yang, Qun Deng and Jinhui Du \\ Central Iron and Steel Research Institute, Beijing 100081, China \\ Xishan Xie, Bing Li, Zhichao Xu and Zhen Cao \\ University of Science and Technology Beijing \\ Beijing 100083, China \\ Zhaoqian Su and Cizheng Jiang \\ Great Wall Steel Works, Sichuan 621704, China
}

\begin{abstract}
Delta-Phase behaviour has important effect on mechanical properties in Alloy718. Structure control on $\delta$ - phase behaviour by forging and followed heat treatment processing has been conducted in this resear ch, simultaneously differ ent quantity, morphology and distribution of $\delta$-phase have been achieved in turbine disk fabrication. Experimental results indicate that $\delta$-phase behaviour has obvious influence on crack propagation. In certain range $\delta$-phase has retardation effect on crack propagation. Crack propagation mechanism and failure anal yses under creep and fatigue conditions have been discussed also.
\end{abstract}

\footnotetext{
Superalloys $718,625,706$ and Various Derivatives 
$\underline{\text { Introduction }}$

Del ta - Phase behaviour has important effect on microstr ucture and mechanical properties in Alloy718. Recently, grain size control in Del ta Processed Alloy $718^{[1]}$ and the influence of $\delta$-phase on stress - rupture notch sensitivity ${ }^{[2]}$ and impact toughness have been studied. ${ }^{[3]}$ The effect of microstructure on crack propagation behaviour has been investigated also ${ }^{[4](5]}$. However, the effect of $\delta$-phase on crack initiation and propagation under creep and fatigue conditions in direct - aging processed Alloy718 (DA718) has been published scarcely.

This investigation concentrates to study the effect of $\delta$-phase on crack initiation and propagation under creep and creep/fatigue inter action conditions in several experimental DA718 disks and crack propagation mechanism has been discussed also.

Materials and experimental methods

Experimental material has been chosen from two VIM + VAR commercial heats of Alloy 718. Ingots were homogenized by 2 step high temperature treatment (first step for Laves - phase sol ution and second step for homogenization of niobium). Forged round bars from two heats were deformed by hydraulic press for pancake making and finally for die-forging disks with different technology and followed same direct aging treatment. Two DA718 disks, designated as $A$ and $B$ shown in Table 1 , have almost same chemical compositions. The grain sizes of disks A and B are almost same in ASTM 10 (Fig. 1). However, the $\delta$-phase behaviour is different, that disk A contains more $\delta$-phase than disk B (see Fig. 1) because of different forging technology.

Table 1. Chemical Compositions (in wt $\%$ ) of two DA718 Disks

\begin{tabular}{|c|c|c|c|c|c|c|c|c|c|c|c|c|}
\hline & C & $\mathbf{N i}$ & $\mathrm{Cr}$ & Mo & $\mathbf{N b}$ & $\mathrm{Ti}$ & Al & B & Mn & $\mathrm{Si}$ & $\mathrm{Fe}$ & $\mathbf{M g}$ \\
\hline Disk A & 0. 037 & 52. 33 & 18. 50 & 3. 08 & 5. 07 & 1. 00 & 0.58 & 0. 005 & 0.02 & $<0.01$ & base & 0.0024 \\
\hline Disk B & 0. 035 & 52. 08 & 18. 97 & 3. 05 & 5. 01 & 1. 00 & 0. 52 & 0. 003 & $<0.10$ & 0.006 & base & 0.0046 \\
\hline
\end{tabular}

Crack propagation behaviour of disk $A$ and $B$ was studied under creep andcreep/fatigue interaction conditions (the load wave diagrams are shown in Figure 2) at $650^{\circ} \mathrm{C}$ by potencial drop method using compact tension specimen $(25 \times 25 \times 10 \mathrm{~mm})$. In order to study the relationship among tensile strengthes, stress rupture properties and crack growth rates, $650^{\circ} \mathrm{C}$ tensile 
and stress rupture tests at $686 \mathrm{MPa}$ were conducted also. The crack path morphology and microstructure for compact tension specimens were analysed by SEM and TEM both.
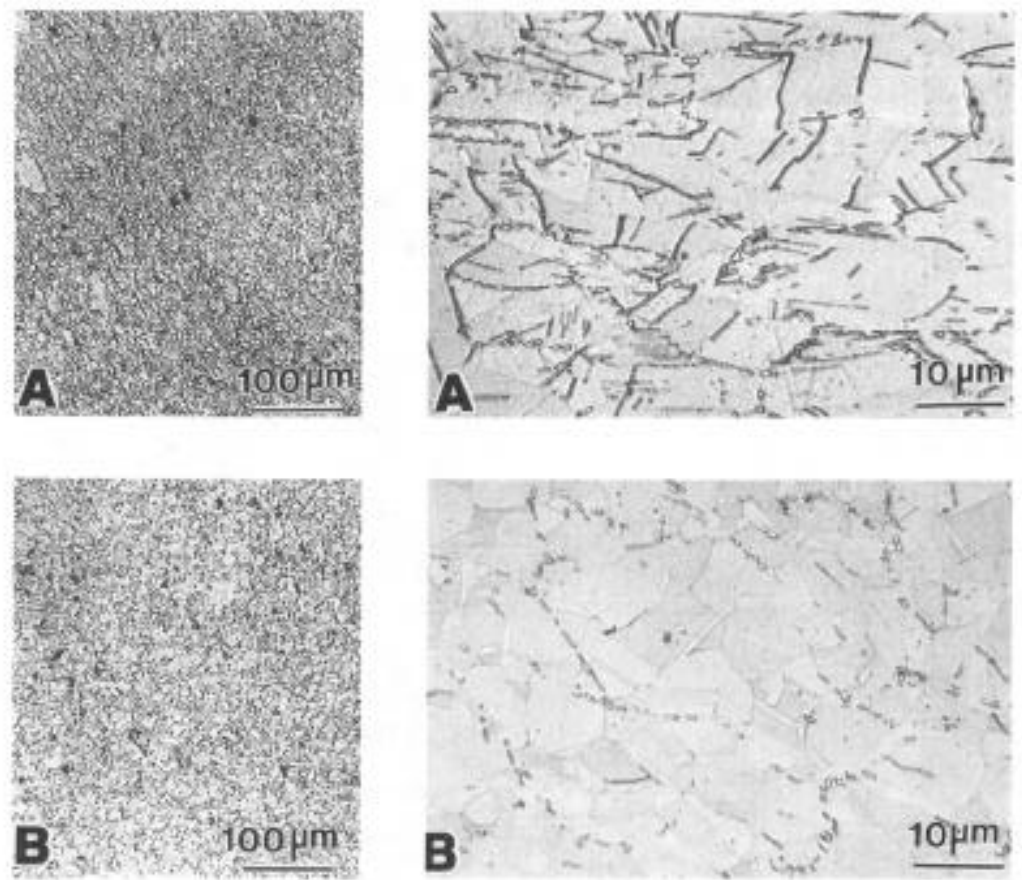

Pigure 1. Microstrueture of two DA718 disks (A-disk A B-disk B)
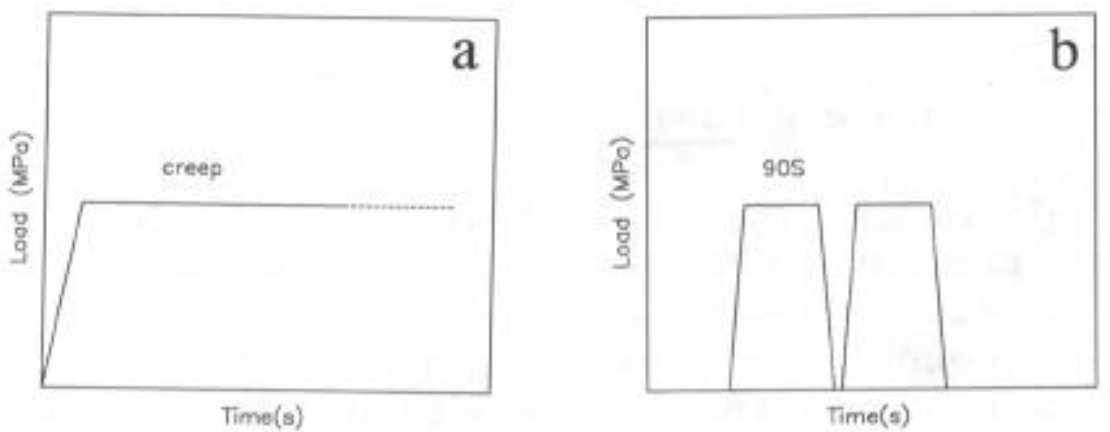
a-Creep
b-Creep/fatigue interaction

Figure 2. Load wave diagrams for crack propagation testa at $650^{\circ} \mathrm{C}$ 


\section{Results and Discussions}

Tensile and stress rupture properties

The ul timate tensilc strengthes (UTS) and yicld strengthes (YS) of 2 experimental DA7 18 disks are almost same at $650^{\circ} \mathrm{C}$ tensile tests as shown in Figure 3 . The stress rupture life of disk $A$ is shorter than that of disk $B$, but the elongation of disk $A$ is larger than that of disk $B$ as shown in Figure 4. However, mechanical properties of tensile and stress rupture tests at $650^{\circ} \mathrm{C}$ for both disks can meet the demand of specification.

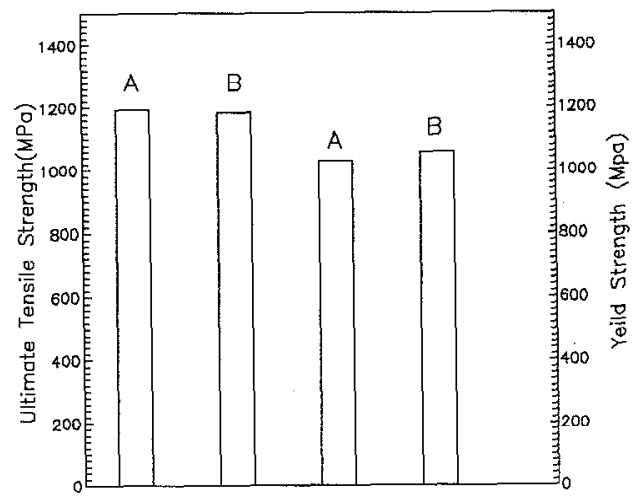

Figure 3. Tensile properties tested at $650^{\circ} \mathrm{C}$ of two disks (A-disk A B-disk B)

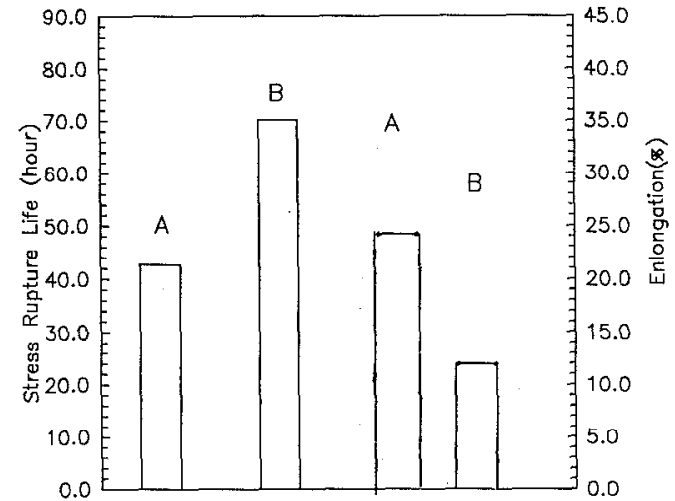

Figure 4. The stress rupture properties tested.at $650^{\circ} \mathrm{C}$ of two disks (A-disk A B-disk B)

Crack initiation and propagation

Figure 5 illustrate the relationship between crack length (a) and time of crack propagation tests under creep and creep/fatigue interaction conditions at $650^{\circ} \mathrm{C}$. The abrupt growth of crack length represents the crack initiation as shown in Figure 5. Disk $A$ has longer time period for crack initiation than disk $B$ under creep/fatigue interaction condition and disk $A$ has unusual long time period almost 70 times longer for crack initiation than disk $B$ under creep test.

Figure 6 and 7 illustrate the crack propagation rate curves (da/dt $-K$ and $\mathbf{d a} / \mathbf{d n}-\Delta \mathbf{k})$ of 2 experimental DA718 disks under creep and creep/fatigue interaction conditions at $650^{\circ} \mathrm{C}$. It can be clearly seen that disk $A$ has lower crack propagation rate than disk $B$ at both test conditions. 

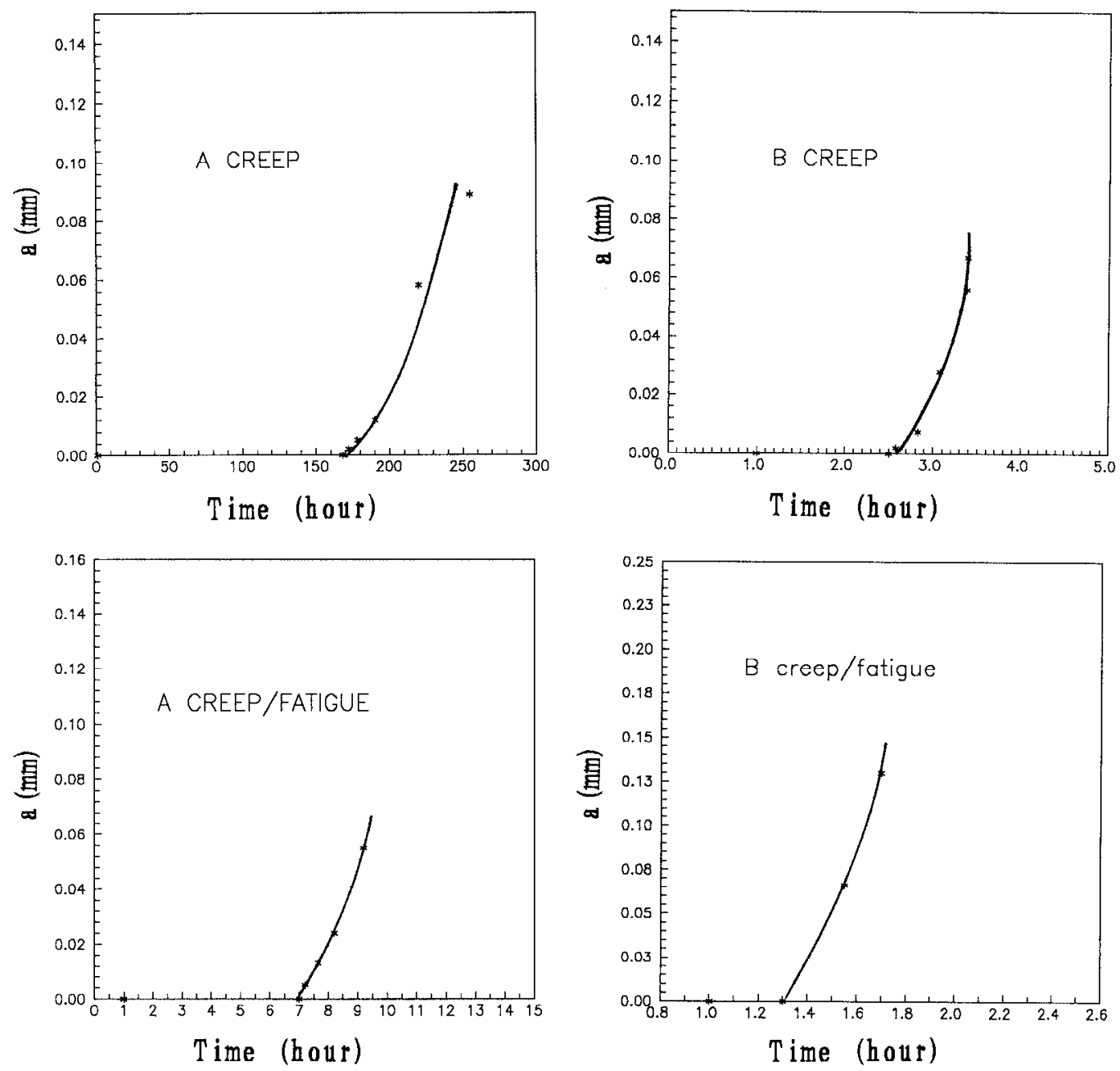

Figure 5. The curves of crack length va time of crack propagation test under creep and creep/fatigue interaction conditions at $650^{\circ} \mathrm{C}$

Fracture surface and crack path analyses

Fracture of compact tension specimens from two DA718 disks with different contents of $\delta$-phase characterizes with intergranular fracture mode under creep condition (see Figure $8 \mathbf{a}$ and $8 \mathbf{b}$ ). The fracture of compact tension spcecimens of both disks still possesses with intergranular fracture mode even at creep/fatigue interaction condition (see Fig. $8 \mathrm{c}$ and $8 \mathrm{~d}$ ), because creep still keeps predominant damage at this cyclic creep test. However, fracture surface of compact tension specimen from disk $A$ with more content of $\delta$-phase possesses more ductile behaviour than that of disk B with less content of $\delta$-phase under creep/fatigue interaction condition (in comparison $8 \mathrm{c}$ with $8 \mathrm{~d}$ ). 


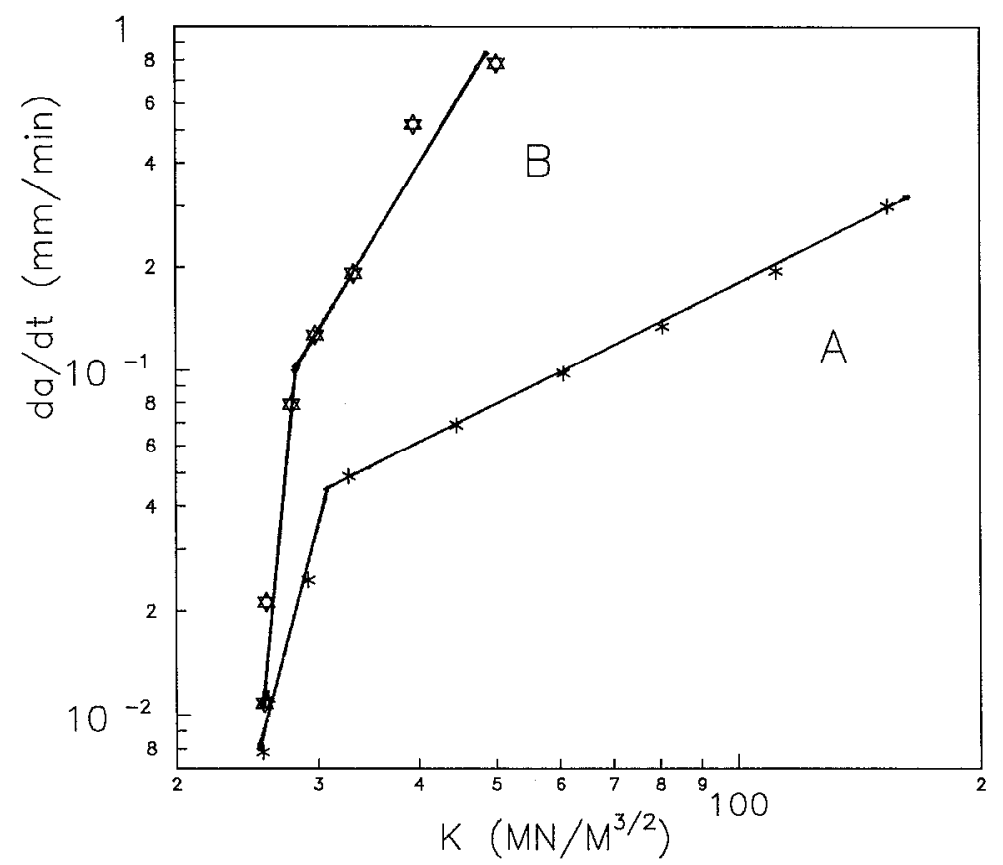

Figure 6. The crack propagation rate curves of two experimental DA718 disks under creep condition at $650^{\circ} \mathrm{C}$

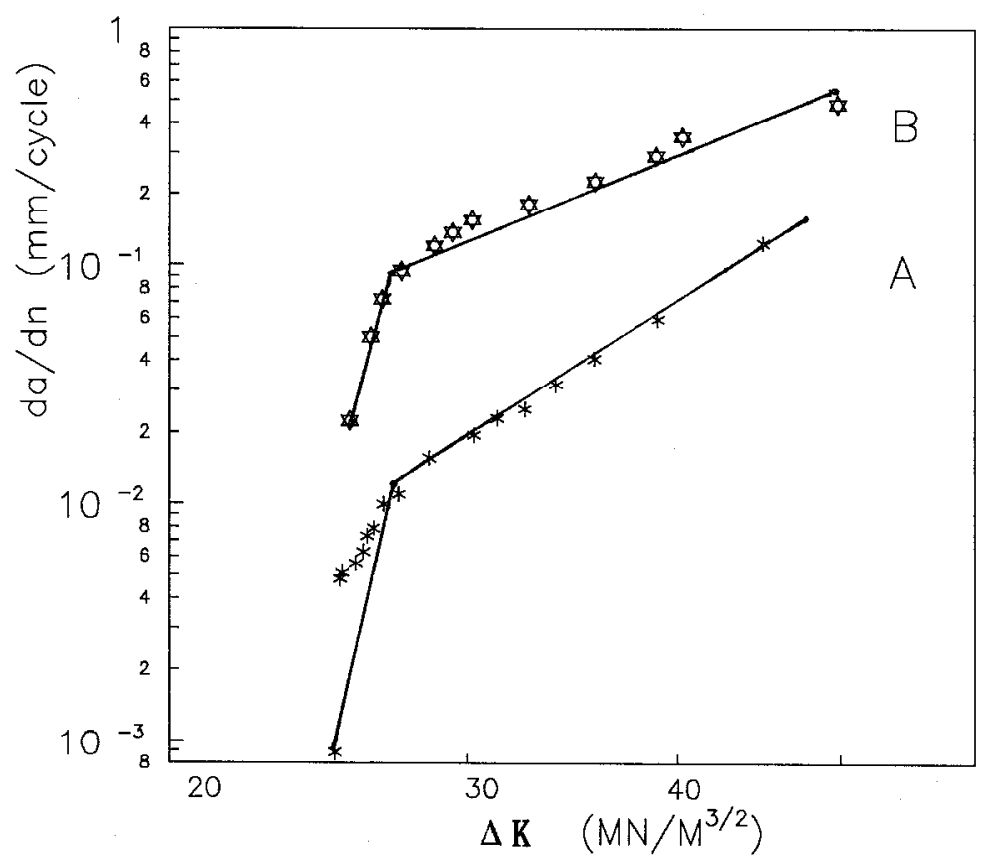

Figure 7. The crack propagation rate curves of two experimental DA718 disks under creep/fatigue interaction condition at $650^{\circ} \mathrm{C}$ 


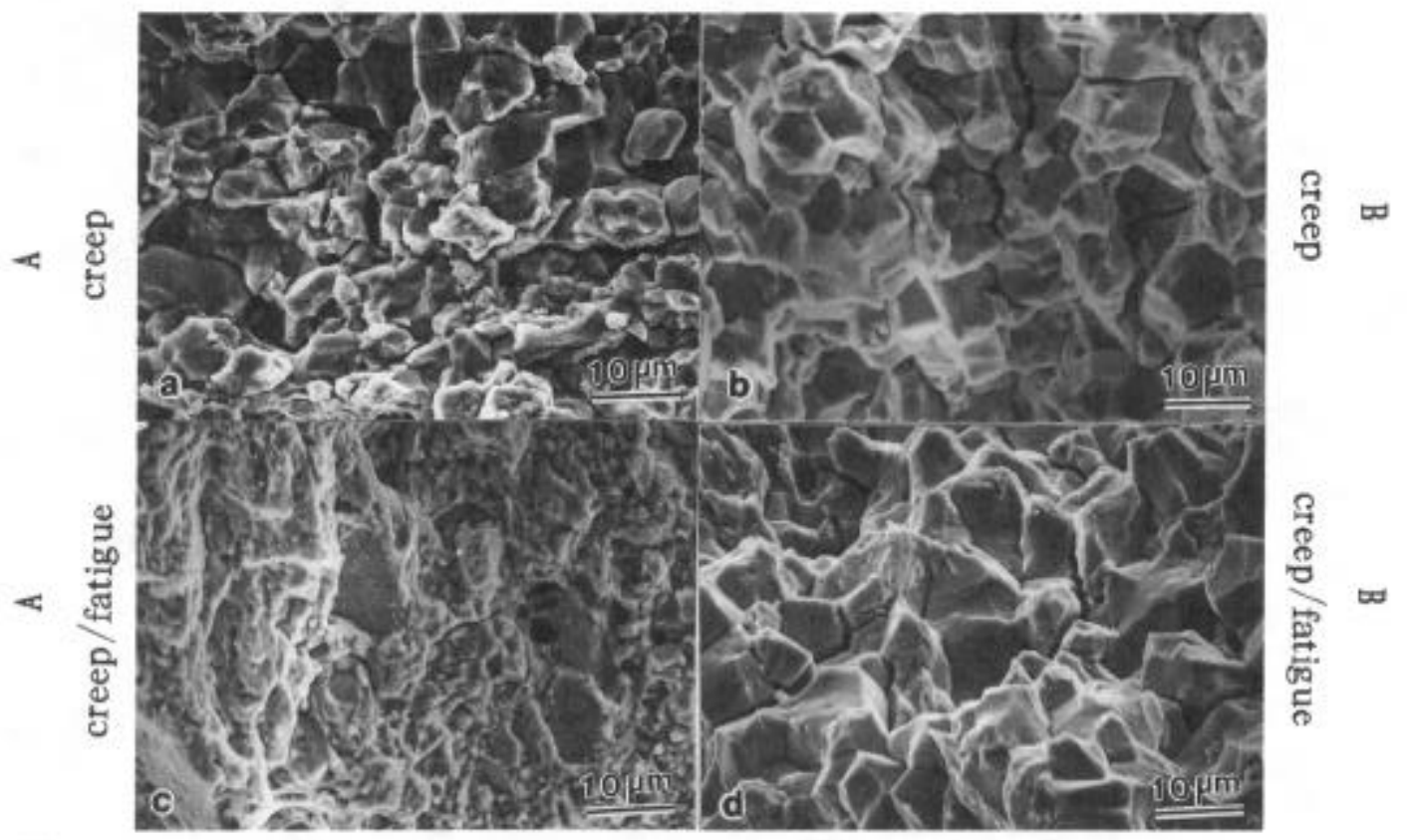

Figure 8. Microstructure of compact tension specimens fracture surfaces tested under creep and creep/fatigue interaction conditions at $650^{\circ} \mathrm{C}$

SEM direct observation on the crack tip of compact tension specimen surface can clearly show the crack path. Figure 9 shows intergranular crack propagation behaviour under creep test condition at the surfaces of compact tension specimens of both DA718 disks. The existance of globular 8 -phase at grain boundaries plays a role as obstacles to block the grain boundary crack propagation.

For further study on the influence of grain boundary $\delta$-phase on intergranular crack propagatioin behaviour, a DA718 disk (designated as disk C) with fine grain size (ASTM 11) and globular $\delta$-phase existence (as shown in Figure 10) was chosen for crack propagation test under creep test. SEM direct observation on crack tip as shown in Figure 11 clearly reveals the blocking effect of grain boundary 8 -phase on intergranular crack propagation under creep condition. The grain boundary crack propagation as show in Figure 11 characterizes with zig - zag path.

Del ta phase behaviour is important in DA718 not only for grain size but also for micro - structure control, especially the grain boundary structure, as shown in Fig. 1 and 10 , that disks A, B and C possess different volume fraction and distribution of $\delta$-phase. Delta phase formation is a diffusion control process and needs concentration of $\mathrm{Nb}$ in it. Figure 12 shows the $\gamma^{\prime \prime}$ and $\gamma^{\prime}$ denuded zone surrounded 8 -phase because of the niobium concentration gradient. 


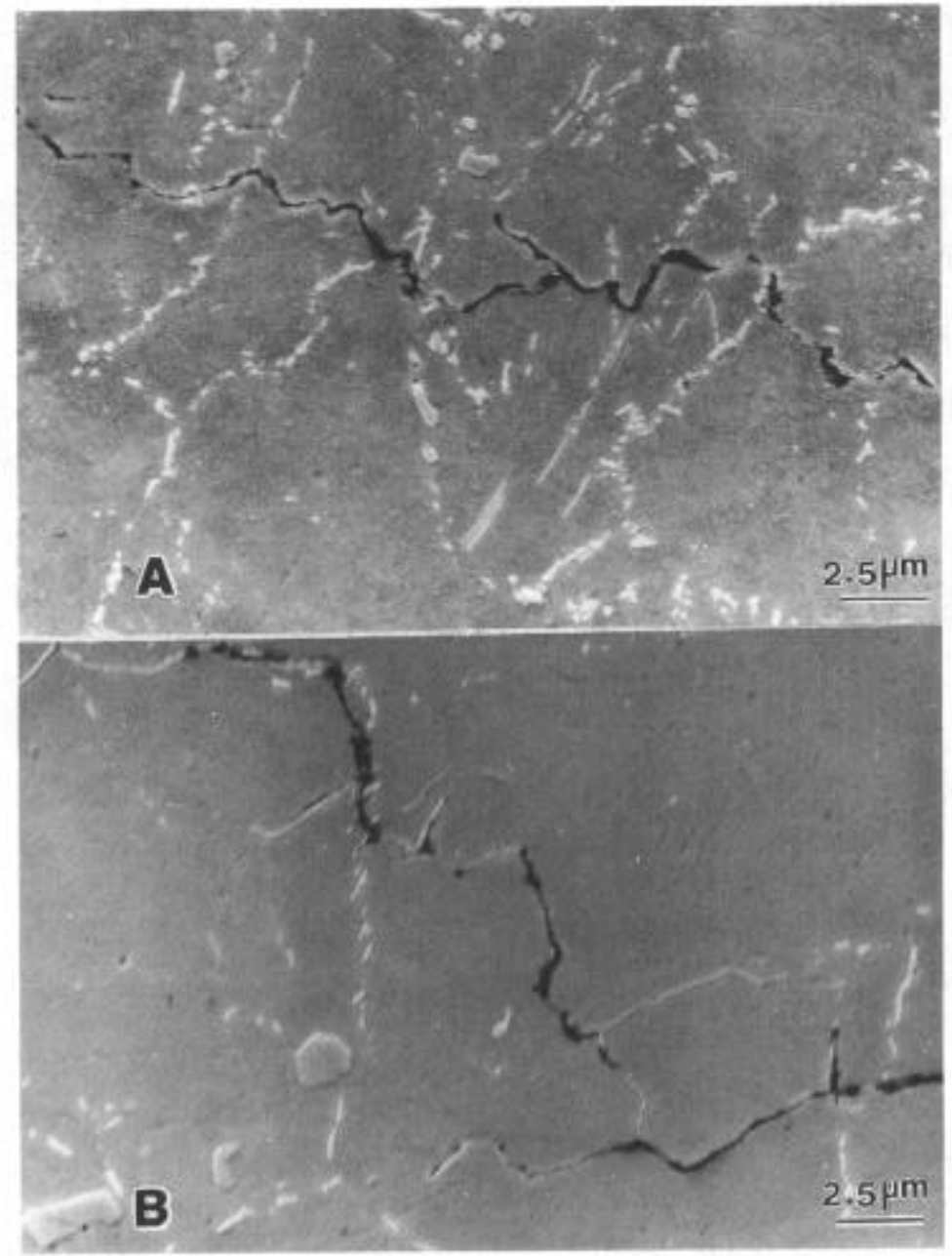

Pigure 9. Micro-crack path on compact tension specimens surfaces, test under creep condition at $650^{\circ} \mathrm{C}$ of disk $A$ and $B$

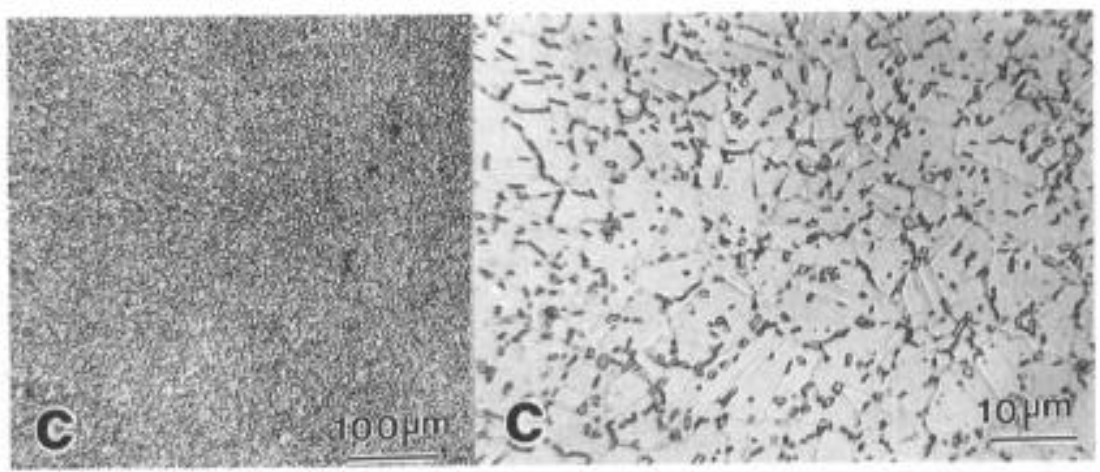

Figure 10. Microstructure of disk C 


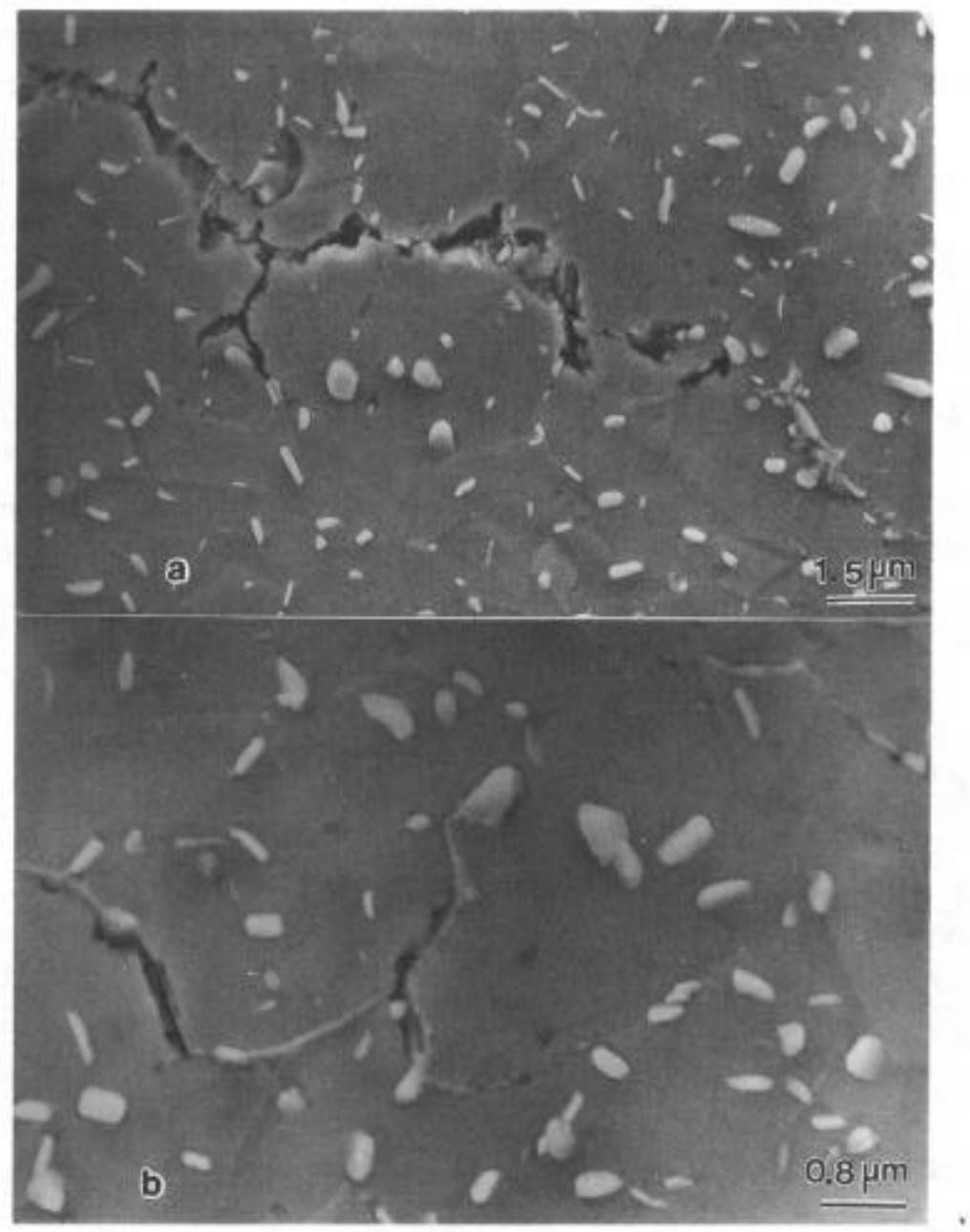

Figure 11. Micro-crack path on compact tension specimens surfaces test under creep condition at $650^{\circ} \mathrm{C}$ of disk C

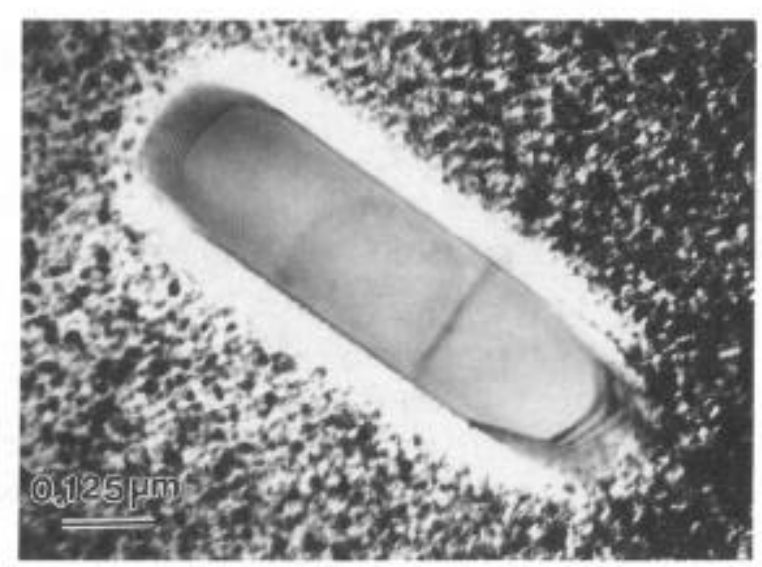

Figure 12. Microstructure of the $\gamma^{\prime}$ and $\gamma^{\prime}$ denuded zone nearby $\delta$-phase 
It can be deduced, that the area surrounded $\delta$-phase possesses high plasticity than the matrix with enough amount of $\gamma^{\prime \prime}$ and $\gamma^{\prime}$ strengthening phases in DA718 matcrial. The existance of certain amount of globular $\delta$-phase at grain boundaries is extremely important for improving the resistance to intergranular crack propagation under creep and creep/fatigue conditions for two reasons :

(1) Globular $\delta$-phase distribution at grain boundaries can block intergranular crack propagation.

(2) The ductile region nearby grain boundaries because of the existance of denuded zone of $\gamma^{\prime \prime}$ and $\gamma^{\prime}$ can relax the stress concentration at grain boundaries, then to retard grain boundary crack initiation and propagation.

$\gamma^{\prime \prime}$ and $\delta$ phase are both rich in niobium. However, $\gamma^{\prime \prime}$ is main strengthening phase in DA718 for keeping high strength, and $\delta$ is not strengthening phase but it is important for ductility improvement. In DA718, the co-existance of $\gamma^{\prime \prime}$ and $\delta$ in structure will both consume $\mathrm{Nb}$ from the certain content of $\mathrm{Nb}$ in Alloy718. Therefore, it is a certain compensation between strength and ductility as shown in Figure 4 . Disk A with more content of 8 -phasc possesses lower stress rupture life but higher elongation than disk $B$ with less content of $\delta$-phase. However, both disks can meet the demand of specification because of the strong strengthening effect of $\gamma^{\prime \prime}$ phase. For a good balance of strength and ductility, especially for improving the resistance to grain boundary crack initiation and propagation, separately precipitated globular $\delta$-phase at grain boundaries has beneficial effect on intergranul ar crack initiation and propagation. Of cause, over volume fraction of $\delta$-phase in DA718, especially more $\delta$-phase formation in grains , will degrade the strength even can not meet the specification.

Concl usions

1. Globular $\delta$-phase distribution at grain boundaries in DA718 has retardation effect on grain boundary crack initiation and propagation at creep and creep/fatigue interaction condition with predominant creep damage at elevated temperatures.

2. The existance of desirable and reasonable amount of $\delta$-phase in DA718 can improve stress rupture ductil ity for keeping enough strength (stress rupture life) to meet the strength requirement of specification.

3. From the point of view of DA718 Alloy disk production $\delta$-phase precipitation control and the balance between strength and ductility are extremely important practical factors for thermo-mechanical processing. 


\section{References}

1. Carlos Ruiz, Abel Obabueki, and Kathy Gillespie," Evalution of the Microstructure and Mechanical Properties of Del ta Processed Alloy 718", Superalloy 1992. TMS, USA (1992) PP. 33-42.

2. Zhuang Jingyun," The Relationship Between $\delta$ - Phase and Notch - Rupture Sensitivity in Alloy GH169", University of Science and Technology Beijing Technical Bulletin, China, Vol. 13, (1992) PP. 177-181.

3. Li Shuqi, Zhuang Jingyun," The Effect of Microstructure on Impact Toughness in Alloy GH169". University of Science and Technology Beijing Technical Bulletin, China, Vol. 13 (1992) PI.182-187.

4. Pineau et al.," The Effect of Microstrucutre and Environment on the Crack Growth Behaviour of Inconel 718 Alloy at $650^{\circ} \mathrm{C}$ under Fatigue, Creep and Combined Loading". Materials Science and Engineering, 56. (1982), PP.143 - 156.

5. Xie Xishan." High Temperature Strengthening and Ductility Improvement in Superalloys". Proceedings of Second National Conference on High Temperature Strength, China, (1988) PP.14-24. 